\title{
Valor nutritivo de silagens de milho colhido em diversos estádios de maturação
}

\author{
Hélio Henrique Vilela ${ }^{1 *}$, Adauton Vilela de Rezende ${ }^{2}$, Paulo de Figueiredo Vieira ${ }^{2}$, Gustavo \\ Augusto Andrade ${ }^{2}$, Antônio Ricardo Evangelista ${ }^{3}$, Geraldo Benedito de Souza Almeida ${ }^{2}$
}

\footnotetext{
${ }^{1}$ Mestrando em Ciência Animal da Universidade Jósé Do Rosário Vellano/UNIFENAS.

2 Universidade José do Rosário Vellano/UNIFENAS.

3 Universidade Federal de Lavras/UFLA.
}

RESUMO - Objetivou-se neste trabalho avaliar as características bromatológicas de silagens de milho produzidas com milho em diversos estádios de maturação. Utilizou-se delineamento experimental de blocos casualizados, com quatro repetições, em esquema de parcelas subdivididas no tempo. Os cultivares Geneze 2004, Agroceres 1051, Pioneer 30S40 e Pioneer 30F90 foram ensilados nos seguintes estádios de maturação: grãos sem linha de leite (SLL); redução da linha de leite em $1 / 3$ do grão (1/3 LL); $1 / 2$ do grão (1/2 LL); $2 / 3$ do grão (2/3 LL); e camada negra $(C N)$ formada. A porcentagem de MS das silagens variou de 26,5 a 45,0\%. As maiores perdas de efluente ocorreram nas silagens dos cultivares AG1051 e P30S40 no estádio sem linha de leite, que não apresentaram perdas a partir do estádio 1/2 LL. Com o avançar do estádio de maturação, observou-se aumento nos valores de $\mathrm{pH}$. Os estádios de maturação influenciaram a porcentagem de PB das silagens, que variou de 10,7 a $8,1 \%$. Os maiores valores de fibra em detergente neutro (FDN) e fibra em detergente ácido (FDA) foram observados nos estádios 2/3 LL e CN. A porcentagem de lignina foi influenciada pelos cultivares e foi maior nas silagens do cultivar P30S40. A digestibilidade in vitro da matéria seca (DIVMS) foi influenciada pelos cultivares e pelos estádios de maturidade, variando de 51,1 a 69,8\%, e foi maior no cultivar P30F90. A ensilagem do milho no estádio 1/2 LL promoveu melhor DIVMS, que reduziu após este estádio. Os cultivares GNZ 2004, AG1051 e P30F90 são mais indicados para ensilagem e o melhor estádio de maturidade para ensilagem desses cultivares é quando os grãos apresentam redução da linha de leite na metade do grão (1/2 LL).

Palavras-chave: digestibilidade, linha de leite, matéria seca

\section{Nutritive value of corn silages harvested at different maturity stages}

\begin{abstract}
This work evaluated the bromatologic characteristics of corn silages, ensiled at different maturity stages. It was used a split plot in time in a randomized block design, with four replicates. Cultivars evaluated were Geneze 2004, Agroceres 1051, Pioneer 30S40 and Pioneer 30F90 ensiled in the following maturity stages: 0\% milk line kernels (SLL), reduction of milk line in $1 / 3$ of the kernel ( $1 / 3 \mathrm{LL}), 1 / 2$ of the kernel $(1 / 2 \mathrm{LL}), 2 / 3$ of the kernel $(2 / 3 \mathrm{LL})$, and formed black layer (CN). The percentage of DM of the silages ranged from $26.5 \%$ to $45.0 \%$. The highest losses of effluents occurred in the silages from the cultivars AG1051 and P30S40, at the SLL stage, with no losses from the 1/2 LL stage. As the maturity stage advanced, increased values of $\mathrm{pH}$ occurred. Maturity stages influenced the percentage of $\mathrm{CP}$ of the silages which ranged from $10.7 \%$ to $8.1 \%$. The greatest values of NDF (neutral detergent fiber) and ADF (acid detergent fiber) were found at the 2/3 LL and CN stages. The percentage of lignin was influenced by the cultivars, with the greatest values observed in the silages from the cultivar P30S40. The IVDDM (in vitro dry matter digestibility) was influenced by cultivar and maturity stage, varying from $51.1 \%$ to $69.8 \%$, with the cultivar P30F90 presenting the greatest IVDDM. The 1/2 LL stage showed better IVDDM, reducing its value after this stage. The cultivars GNZ 2004, AG1051 and P30F90 are more indicated for ensiling and the best maturity stage for ensiling these two cultivars was when grains presented reduction of the milk line in half of the kernel $(1 / 2 \mathrm{LL})$.
\end{abstract}

Key Words: digestibility, dry matter, milk line

\section{Introdução}

Nas regiões Sudeste e Centro-Oeste do Brasil, as variações climáticas ocasionam estacionalidade na produ- ção de forrageiras durante o inverno. É necessário, portanto, que se produza durante o verão um alimento de boa qualidade e que possa ser armazenado e conservado para ser fornecido aos animais, principalmente os ruminantes,

Este artigo foi recebido em 26/2/2007 e aprovado em 25/2/2008.

Correspondências devem ser enviadas parah2vilela@yahoo.com.br.

* Endereço atual: R. José Monte Raso,58, Centro, Boa Esperança, MG, CEP:37170-000. 
durante o período de escassez de forragem. Segundo Nussio (1997), a silagem de milho é um volumoso que, apesar de mais caro, promove melhor resposta no ganho de peso e na produção de leite quando fornecido a bovinos.

O estádio de maturação em que as forrageiras são colhidas e ensiladas tem sido um dos fatores que mais alteram a qualidade e o valor nutritivo da silagem. Geralmente, à medida que avança o estádio de maturação das plantas, ocorrem alterações na composição bromatológica das silagens, como aumento do teor de matéria seca (MS) e redução nos de proteína bruta (Rodrigues et al., 1996).

A produção de efluente é influenciada por fatores como teor de MS da cultura ensilada, tipo de silo, grau de compactação e processamento físico da forragem. Em forragens ensiladas com aproximadamente 30\% de MS, a produção de efluente pode ser pouco significativa (Haigh, 1999).

As diferenças na digestibilidade entre cultivares de milho podem estar relacionadas à porcentagem de grãos ou de espigas para determinado estádio de crescimento da planta e à composição morfológica, que difere muito entre cultivares. Entretanto, essa variação na digestibilidade ocorre principalmente em virtude das diferenças na digestibilidade da parede celular (Andrieu et al., 1993).

De acordo com Scwarz et al. (1996), o valor nutricional diferente entre as partes da planta, o que influencia diretamente a degradabilidade e o valor energético da silagem, que dependem da participação da espiga, das folhas e dos colmos no material a ser ensilado. Segundo Bal et al. (2000), o valor nutritivo da planta de milho para silagem é afetado por vários fatores, como: a quantidade de grãos, o teor de FDN da fração haste, a digestibilidade da FDN, o teor de amido no grão, a digestibilidade do amido e os teores de óleo e proteína.

Embora o milho seja a planta mais utilizada na ensilagem, é preciso observar o grau de maturação ideal para colheita da planta no intuito de se estabelecer o efeito do grau de maturação da planta sobre o valor nutritivo da silagem. Objetivou-se por meio desta pesquisa avaliar a influência do estádio de maturação sobre o valor nutritivo das silagens de quatro cultivares de milho.

\section{Material e Métodos}

O experimento foi conduzido durante o ano agrícola de 2005/2006, em Latossolo vermelho escuro (LE), de acordo com Silva (1997). A fertilidade do solo foi determinada em amostras retiradas na profundidade de $0-20 \mathrm{~cm}$. Na análise, foram obtidos os seguintes resultados: textura - argilosa; pH em água - 5,9; P - 4,9 mg/dm³ $\mathrm{K}^{+}-59,0$ mg/dm³ Ca $^{++}$-
2,9 cmolc $/ \mathrm{dm}^{3} ; \mathrm{Mg}^{++}-0,9 \mathrm{cmolc} / \mathrm{dm}^{3} ; \mathrm{Al}^{+++}-0$ cmolc $/ \mathrm{dm}^{3}$; $\mathrm{H}^{+}+\mathrm{Al}^{+++}-2,9 \mathrm{cmolc} / \mathrm{dm}^{3}$; soma de bases trocáveis (S) 4,0 cmolc $/ \mathrm{dm}^{3}$; CTC efetiva (t) $-4,0$ cmolc/ $/ \mathrm{dm}^{3}$; CTC a pH 7,0 (T) - 6,9 cmolc/ $\mathrm{dm}^{3}$; saturação de Al da CTC efetiva (m) - 0\%, saturação de bases da CTC a pH 7,0 (V) - 55,7\%; matéria orgânica - 2,0 dag/kg; e P - rem - 19,6 mg/L.

O local possui altitude média de $880 \mathrm{~m}$ e a precipitação média durante o período experimental (novembro de 2005 a março de 2006) foi de $181,56 \mathrm{~mm}$, com temperaturas médias de máxima e mínima de 30,8 e $18,4^{\circ} \mathrm{C}$.

A correção da acidez do solo foi feita pelo método de saturação de bases, com aplicação manual a lanço de calcário dolomítico (1.061 kg/ha) com PRNT de 80\% visando elevar a saturação de bases a $70 \% 60$ dias antes do plantio. A adubação de plantio e a semeadura foram realizadas manualmente no dia 7 de novembro de 2005, em sulcos de $10 \mathrm{~cm}$ de profundidade utilizando-se $400 \mathrm{~kg} / \mathrm{ha}$ da fórmula 08-28-16 + 0,3\% de Zn, conforme recomendação da Comissão de Fertilidade do Solo do Estado de Minas Gerais (CFSEMG, 1999), e dez sementes por metro linear. Quando as plantas atingiram $20 \mathrm{~cm}$, foi realizado um desbaste, obtendo-se um estande de 62.500 plantas/ha. Foram realizadas manualmente duas adubações de cobertura no milho entre as linhas de plantio utilizando-se para cada adubação 437,50 kg da fórmula 20-00-20. A primeira adubação foi realizada 30 dias após o plantio e a segunda, com 45 dias. Aos 36 dias após o plantio, realizou-se também uma adubação foliar utilizando-se o adubo foliar Starter da empresa Stoller ${ }^{\circledR}$ na dosagem de 2,0 L/ha. Os demais tratos culturais e fitossanitários foram feitos segundo recomendações técnicas para a cultura.

O delineamento experimental foi em blocos casualizados, com quatro repetições, em esquema de parcelas subdivididas no tempo. As parcelas incluíram os tratamentos principais (cultivares) e as subparcelas, os tratamentos secundários (estádios de maturação para ensilagem). Os cultivares avaliados foram: Geneze 2004 (GNZ 2004), Agroceres 1051 (AG 1051), Pioneer 30S40 (P30S40) e Pioneer 30F90 (P30F90). Os estádios de maturação dos grãos para ensilagem foram: sem linha de leite (SLL); redução da linha de leite em $1 / 3$ do grão (1/3 LL); linha de leite em $1 / 2$ do grão (1/2 LL); 2/3 do grão (2/3 LL); e camada negra (CN) formada.

As parcelas foram compostas de quatro linhas espaçadas a 0,8 m com $22 \mathrm{~m}$ de comprimento e foram separadas uma da outra por uma linha de plantio entre um bloco e outro. As subparcelas foram separadas por um espaçamento de $0,5 \mathrm{~m}$. A área de cada parcela foi de $70,4 \mathrm{~m}^{2}$ e a das subparcelas de $12,8 \mathrm{~m}^{2}$. A área total utilizada no experimento foi de $1.360,4 \mathrm{~m}^{2}$

Semanalmente, foi retirada uma espiga para acompanhamento da redução da linha de leite do grão. Observado o 
ponto de colheita, todas as plantas da subparcela foram colhidas manualmente a $10 \mathrm{~cm}$ do solo e picadas em picadeira estacional, com tamanho médio de partícula de 2 a $3 \mathrm{~cm}$. Uma amostra foi retirada para determinação da MS e parte do material foi ensilada em silos de PVC (10 cm de diâmetro, $50 \mathrm{~cm}$ de altura e volume $0,0039 \mathrm{~m}^{3}$ ). Em cada silo foram colocados 2,1 kg de silagem para obtenção de uma compactação de $550 \mathrm{~kg} / \mathrm{m}^{3}$. Os silos foram fechados com tampas dotadas de válvula tipo "Bünsen" e lacrados com fita adesiva. No fundo de cada silo, colocou-se areia $(0,5 \mathrm{~kg})$ separada da silagem por duas telas de sombrite, que funcionaram como dreno para efluente.

Decorridos 30 dias da ensilagem, os silos foram abertos e o conteúdo superior $(10 \mathrm{~cm})$ de cada silo foi descartado. O material central do silo foi homogeneizado e retirada uma amostra para determinação da matéria seca (MS). Estas amostras foram trituradas em moinho do tipo Willey com peneira de crivos de $1 \mathrm{~mm}$ e utilizadas para avaliação das características bromatológicas da silagem.

No momento em que os silos foram abertos, o $\mathrm{pH}$ foi avaliado utilizando-se um potenciômetro Beckman Expandomatic SS-2 pelo método descrito por Silva \& Queiroz (2002).

A porcentagem de MS da forragem e das silagens foi determinada segundo metodologia da AACC (1976). A perda de efluente foi quantificada pela seguinte expressão: $\mathrm{PE}=(\mathrm{PSAF}-\mathrm{PSAI}) / \mathrm{MNI} * 1000: \mathrm{PE}=$ produção de efluente ( $\mathrm{kg} / \mathrm{t}$ de matéria natural), PSAF = peso do conjunto silo, areia e tela após a abertura (kg), PSAI = peso do conjunto silo, areia e tela antes da ensilagem $(\mathrm{kg}), \mathrm{MNI}=$ quantidade de forragem ensilada $(\mathrm{kg})$.

O teor de nitrogênio foi determinado utilizando-se o aparelho de destilação a vapor micro-Kjedahl, conforme a AOAC (1970) e o teor de PB calculado utilizando-se o fator de conversão 6,25. As porcentagens de FDN e FDA foram calculadas segundo metodologia proposta por Silva \& Queiroz (2002), enquanto a lignina foi determinada por meio de hidrólise ácida, de acordo com Van Soest et al. (1991). A DIVMS foi determinada de acordo com o método das duas etapas de Tilley \& Terry (1963), descritas por Silva \& Queiroz (2002). Os dados obtidos foram submetidos a análises de variância utilizando-se o programa estatístico SISVAR (Ferreira, 2000) e as médias comparadas pelo teste de Scott-Knott a 5\% de significância.

\section{Resultados e Discussão}

As maiores porcentagens de MS observadas para as silagens dos cultivares GNZ 2004 e P30F90 no estádio SLL (Tabela 1) podem ser explicadas pela maior porcentagem de
MS desses cultivares no momento do corte. O fator genético pode ter influenciado o teor de MS do cultivar GNZ 2004, que mais precoce em comparação aos demais. No estádio de corte SLL, houve aumento na porcentagem de MS nas silagens dos cultivares AG1051, P30S40 e P30F90, o que está relacionado à maior perda de efluente nesses cultivares (Tabela 2).

De modo geral, o teor de MS das silagens produzidas com milho no estádio 1/2 LL esteve na faixa ideal, que, segundo Nussio (1991), é de 30 a 37\% para que se tenha boa fermentação do material ensilado e garanta condições para obtenção de silagens de boa qualidade. As maiores porcentagens de MS foram observadas nas silagens produzidas com milho no estádio de corte (CN). Esses valores de MS podem proporcionar condições favoráveis ao aparecimento de fungos, leveduras e microrganismos aeróbicos, em virtude da dificuldade de compactação, que reduz a expulsão de ar e promove perdas no valor nutritivo das silagens.

Os resultados obtidos com as silagens do estádio 1/2 LL (34,8\% MS) e CN (43,1\% MS) foram superiores aos observados por Corrêa et al. (2002), que registraram para estes mesmos estádios de maturação teores de MS de 31,7 e 41,7\%. Com exceção do cultivar GNZ 2004, todos os demais apresentaram redução $(\mathrm{P}<0,05)$ na perda de efluente conforme avançou o estádio de maturação. A partir do estádio 1/2 LL, não foi detectada perda de efluente, o que pode ser explicado pela maior porcentagem de MS das plantas ensiladas a partir deste estádio.

A maior perda de efluente para os cultivares AG1051 e P30S40 no estádio SLL é explicada pelo fato de esses cultivares apresentarem menor porcentagem de MS quando ensilados neste estádio. Reis \& Rosa (2001) verificaram que silagens com menos de $30 \%$ de MS podem apresentar elevadas quantidades de efluente. O cultivar GNZ 2004 não diferiu $(\mathrm{P}>0,05)$ entre os estádios de corte, uma vez que esse cultivar possui uma faixa ideal de MS para ensilagem desde o primeiro estádio de corte, em virtude de sua maior precocidade.

A partir do estádio 1/3 LL, não foram observadas diferenças entre os cultivares, o que está relacionado aos maiores teores de MS das plantas ensiladas. Segundo Haigh (1999), a produção de efluente é influenciada pelo teor de MS da cultura, pois, em forrageiras ensiladas com aproximadamente $30 \%$ de MS, a produção de efluente pode ser pouco significativa. Alguns estudos têm comprovado relação negativa entre o teor de MS na ensilagem e o volume de efluente produzido, uma vez que, por meio do efluente são drenados em solução componentes nitrogenados, açúcar e minerais, ocasionando perdas no valor nutritivo do alimento (O’ Donnel et al., 1997; Haigh, 1999). 
Os valores de $\mathrm{pH}$ das silagens (Tabela 3) apresentaram amplitude de variação de 3,38 a 3,68 e aumentaram à medida que avançou o estádio de maturação das plantas, em razão da maior porcentagem de MS nas silagens. Nos cultivares GNZ 2004 e P30F90, os valores de pH foram maiores no quinto estádio, enquanto nos cultivares AG1051 e P30S40 foram maiores a partir do quarto estádio de corte. Esse resultado pode ser explicado pela maior porcentagem de MS no quarto e quinto estádios de corte, como observado por Woolford (1984), que constatou que silagens com maior conteúdo de MS estabilizaram em pH mais alto.

No estádio de corte $1 / 2$ LL, não houve diferenças no pH entre os cultivares, o que está relacionado à proximidade das porcentagens de MS nas silagens deste estádio de corte. Os maiores valores de $\mathrm{pH}$ observados para os cultivares GNZ 2004 e AG1051 no estádio 2/3 LL pode ser atribuído ao fato de as silagens produzidas com esses cultivares apresentarem maior porcentagem de MS.

De modo geral, os cultivares ensilados a partir do estádio 1/2 LL apresentaram pH dentro da faixa normal para silagens de milho, que, segundo Borreani et al. (2002), é de 3,5 a 3,7. Os resultados foram semelhantes aos encontrados por Lavezzo et al. (1997a), 3,38 a 3,62, ao ensilarem o milho com os grãos no ponto leitoso, pamonha, farináceo e semiduro, e inferiores aos observados por Cesarino (2006), que registrou valores de $\mathrm{pH}$ de 3,68 a 3,79 em silagens produzidas quando os grãos se encontravam na metade da linha de leite.

A amplitude de variação na porcentagem de $\mathrm{PB}$ foi de 11,2 a 7,3\% (Tabela 4). A porcentagem de PB, em todas as silagens, reduziu de acordo com o avanço no estádio de maturação das plantas. A maior porcentagem de PB foi observada no estádio SLL, o que está relacionado ao fato de os cultivares apresentarem neste estádio de corte menor porcentagem de MS, além de maior participação de folhas, o que proporciona maior porcentagem de $\mathrm{PB}$, visto que a maior parte da proteína se encontra nas folhas. A maior porcentagem de PB no estádio SLL também pode estar associada aos menores valores de $\mathrm{pH}$, que propiciam a fermentação e a preservação da proteína. A redução na

Tabela 1 - Porcentagem de matéria seca (MS) da forragem no momento do corte e das silagens de milho colhido em diversos estádios de maturação

\begin{tabular}{|c|c|c|c|c|c|}
\hline \multirow{3}{*}{ Estádio de maturação } & \multicolumn{4}{|c|}{ Cultivar } & \multirow{3}{*}{ Média } \\
\hline & GNZ 2004 & AG1051 & P30S40 & P30F90 & \\
\hline & \multicolumn{4}{|c|}{ \%MS } & \\
\hline SLL silagem & $30,7 \mathrm{Ea}$ & $27,6 \mathrm{~Eb}$ & $26,5 \mathrm{~Eb}$ & $30,4 \mathrm{Da}$ & $28,8 \mathrm{E}$ \\
\hline SLL forragem & $30,3 \mathrm{Da}$ & $24,6 \mathrm{Db}$ & $24,2 \mathrm{~Eb}$ & $28,4 \mathrm{Da}$ & $26,9 \mathrm{E}$ \\
\hline 1/3 LL silagem & $32,3 \mathrm{Da}$ & 29,9Db & $29,1 \mathrm{Db}$ & $30,8 \mathrm{Db}$ & $30,5 \mathrm{D}$ \\
\hline 1/3 LL forragem & $32,5 \mathrm{Ca}$ & $29,8 \mathrm{Ca}$ & $29,4 \mathrm{Da}$ & $30,3 \mathrm{Da}$ & $30,5 \mathrm{D}$ \\
\hline 1/2 LL silagem & $34,9 \mathrm{Ca}$ & $35,2 \mathrm{Ca}$ & $35,2 \mathrm{Ca}$ & $34,1 \mathrm{Ca}$ & $34,8 \mathrm{C}$ \\
\hline 1/2 LL forragem & $34,6 \mathrm{Cb}$ & $38,0 \mathrm{Ba}$ & $36,2 \mathrm{Ca}$ & $34,2 \mathrm{Cb}$ & $35,7 \mathrm{C}$ \\
\hline 2/3 LL silagem & $40,9 \mathrm{Ba}$ & $42,1 \mathrm{Ba}$ & $39,0 \mathrm{Bb}$ & $36,5 \mathrm{Bc}$ & $39,6 \mathrm{~B}$ \\
\hline 2/3 LL forragem & $39,9 \mathrm{Bb}$ & $44,4 \mathrm{Aa}$ & $40,9 \mathrm{Bb}$ & $38,8 \mathrm{Bb}$ & $41,0 \mathrm{~B}$ \\
\hline CN silagem & $45,0 \mathrm{Aa}$ & $44,8 \mathrm{Aa}$ & $40,6 \mathrm{Ab}$ & $42,1 \mathrm{Ab}$ & $43,1 \mathrm{~A}$ \\
\hline CN forragem & $46,4 \mathrm{Aa}$ & $45,3 \mathrm{Aa}$ & $43,7 \mathrm{Aa}$ & 43,6Aa & $44,7 \mathrm{~A}$ \\
\hline Média silagem & $36,8 a$ & $35,9 a$ & $34,1 b$ & $34,8 b$ & 35,4 \\
\hline Média forragem & $36,8 a$ & $36,4 a$ & 34,9b & $35,0 b$ & 35,7 \\
\hline
\end{tabular}

Médias seguidas da mesma letra minúscula na linha e maiúscula na coluna não diferem $(P<0,05)$ entre si pelo teste Scott-Knott. $\mathrm{SLL}=$ sem linha de leite, $\mathrm{LL}=$ linha de leite, $\mathrm{CN}=$ camada negra

Tabela 2 - Perda de efluente nas silagens de milho (kg/t MN) colhido em diversos estádios de maturação

\begin{tabular}{|c|c|c|c|c|c|}
\hline \multirow{3}{*}{ Estádio de maturação } & \multicolumn{4}{|c|}{ Cultivar } & \multirow{3}{*}{ Média } \\
\hline & GNZ 2004 & AG1051 & P30S40 & P30F90 & \\
\hline & \multicolumn{4}{|c|}{ Perda por efluente } & \\
\hline SLL & 0,9 Ac & $17,8 \mathrm{Aa}$ & $18,1 \mathrm{Aa}$ & $8,9 \mathrm{Ab}$ & $11,4 \mathrm{~A}$ \\
\hline 1/3 LL & $0,9 \mathrm{Aa}$ & $2,4 \mathrm{Ba}$ & $2,4 \mathrm{Ba}$ & $0,9 B \mathrm{a}$ & $1,6 \mathrm{~B}$ \\
\hline 1/2 LL & $0,0 \mathrm{Aa}$ & $0,0 \mathrm{Ca}$ & $0,0 \mathrm{Ca}$ & $0,0 \mathrm{Ba}$ & $0,0 \mathrm{C}$ \\
\hline 2/3 LL & $0,0 \mathrm{Aa}$ & $0,0 \mathrm{Ca}$ & $0,0 \mathrm{Ca}$ & $0,0 \mathrm{Ba}$ & $0,0 \mathrm{C}$ \\
\hline $\mathrm{CN}$ & $0,0 \mathrm{Aa}$ & $0,0 \mathrm{Ca}$ & $0,0 \mathrm{Ca}$ & $0,0 \mathrm{Ba}$ & $0,0 \mathrm{C}$ \\
\hline Média & $0,3 c$ & $4,0 \mathrm{a}$ & $4,1 \mathrm{a}$ & $1,9 \mathrm{~b}$ & 2,6 \\
\hline
\end{tabular}

Médias seguidas da mesma letra minúscula na linha e maiúscula na coluna não diferem $(P<0,05)$ entre si pelo teste Scott-Knott.

SLL = sem linha de leite, $L L=$ linha de leite, $C N=$ camada negra . 
porcentagem de PB pode ser atribuída ao aumento na produção de MS, que causa diluição da proteína na MS.

Os resultados observados para os cultivares GNZ 2004, AG 1051 e P30F90 ensilados com os grãos na metade da linha de leite foram superiores aos observados por Mendes (2006), que encontraram média de 6,9, 7,2 e 6,9\% de PB para os mesmos cultivares ensilados com os grãos na metade da linha de leite. Possivelmente, a maior quantidade de nitrogênio aplicada em cobertura (175 kg/ha) em relação ao experimento de Mendes (2006) (148,5 kg/ha) tenha contribuído para que os valores observados fossem superiores.

De modo geral, observou-se aumento $(\mathrm{P}<0,05)$ nos teores de FDN e FDA à medida em que se avançou o estádio de maturação (Tabela 5), o que pode ser explicado pelo acúmulo de tecidos estruturais com o desenvolvimento fisiológico da planta.

A maior porcentagem de FDN e FDA no estádio SLL para o cultivar P30S40 pode estar relacionada à alta perda de efluente nas silagens, pois, segundo Van Soest (1994), a fração fibrosa do material ensilado pode ser acrescida percentualmente em condições de intensa formação de efluente, uma vez que os componentes solúveis em água reduzem proporcionalmente ao aumento nos constituintes da parede celular. No cultivar P30F90, observou-se no estádio SLL porcentagem de FDN inferior às demais, o que provavelmente pode ser explicado pela menor perda de efluente em relação aos cultivares AG1051 e P30S40. Segundo Van Soest (1994), teores de FDN superiores a 55\% da MS são negativamente correlacionados ao consumo e à digestibilidade. Assim, é possível que a maioria das silagens tenha apresentado boas porcentagens de FDN.

Nesta pesquisa, não foi observada redução nos teores de FDN com o avançar do estádio de maturação, o que está relacionado à tendência de lignificação. Esses resultados contrariam os obtidos por Cabral et al. (2002), que observaram redução nos teores de FDN, de 73,4\%, nas silagens sem grãos, para 29,3\%, nas silagens com 60,0\% de grãos. Diferem também dos relatos de Lavezzo et al. (1997b), que, avaliando cultivares de milho ensilados com os grãos nos estádios leitoso, farináceo, ponto pamonha e semiduro, observaram redução nos teores de FDN nas silagens (de 61,5 para 56,4\%) com o avanço do estádio de maturação, como resultado da maior participação de grãos no material ensilado. Os valores observados neste estudo para os cultivares GNZ 2004, AG1051 e P30F90 ensilados no estádio de corte 1/2 LL foram superiores aos registrados por Mendes (2006) para os mesmos cultivares, também ensilados com os grãos na metade da linha de leite (47,6; 42,2 e 40,9\%, respectivamente).

As porcentagens de FDA variaram de 22,9 a 31,6\%. Fancelli \& Dourado Neto (2000) consideraram ideais para silagens de milho valores de FDA em torno de 30\%, portanto, os valores observados podem ser considerados

Tabela 3 - Potencial hidrogeniônico $(\mathrm{pH})$ de silagens de milho colhido em diversos estádios de maturação

\begin{tabular}{|c|c|c|c|c|c|}
\hline \multirow{3}{*}{ Estádio de maturação } & \multicolumn{4}{|c|}{ Cultivar } & \multirow{3}{*}{ Média } \\
\hline & GNZ 2004 & AG1051 & P30S40 & P30F90 & \\
\hline & \multicolumn{4}{|c|}{$\mathrm{pH}$} & \\
\hline SLL & $3,55 \mathrm{Ca}$ & $3,52 \mathrm{Ca}$ & $3,45 \mathrm{Cb}$ & $3,45 \mathrm{Cb}$ & $3,49 \mathrm{D}$ \\
\hline 1/3 LL & $3,50 \mathrm{Ca}$ & $3,46 \mathrm{Da}$ & 3,38Ba & $3,45 \mathrm{Cb}$ & $3,45 \mathrm{E}$ \\
\hline 1/2 LL & $3,52 \mathrm{Ca}$ & $3,55 \mathrm{Ba}$ & $3,48 \mathrm{Ba}$ & $3,52 \mathrm{Ba}$ & $3,52 \mathrm{C}$ \\
\hline 2/3 LL & 3,61Bа & 3,61Aa & $3,54 \mathrm{Ab}$ & 3,54Bb & $3,57 \mathrm{~B}$ \\
\hline $\mathrm{CN}$ & $3,68 \mathrm{Aa}$ & $3,60 \mathrm{Ab}$ & $3,59 \mathrm{Ab}$ & 3,59Ab & $3,61 \mathrm{~A}$ \\
\hline Média & $3,57 a$ & $3,55 a$ & $3,49 b$ & $3,51 b$ & 3,53 \\
\hline
\end{tabular}

Médias seguidas da mesma letra minúscula na linha e maiúscula na coluna não diferem $(P<0,05)$ entre si pelo teste Scott-Knott. $\mathrm{SLL}=$ sem linha de leite, $\mathrm{LL}=$ linha de leite, $\mathrm{CN}=$ camada negra

Tabela 4 - Porcentagem de proteína bruta (PB) de silagens de milho colhido em diversos estádios de maturação

\begin{tabular}{|c|c|c|c|c|c|}
\hline \multirow{2}{*}{ Estádio de maturação } & \multicolumn{4}{|c|}{ Cultivar } & \multirow[b]{2}{*}{ Média } \\
\hline & GNZ 2004 & AG1051 & P30S40 & P30F90 & \\
\hline & \multicolumn{4}{|c|}{ PB (\%MS) } & \\
\hline SLL & $11,2 \mathrm{~A}$ & $10,5 \mathrm{~A}$ & $11,0 \mathrm{~A}$ & $10,1 \mathrm{~A}$ & $10,7 \mathrm{~A}$ \\
\hline 1/3 LL & $9,3 \mathrm{~B}$ & $9,5 \mathrm{~B}$ & $9,1 \mathrm{~B}$ & $9,1 \mathrm{~B}$ & $9,2 \mathrm{~B}$ \\
\hline $1 / 2 \mathrm{LL}$ & $8,5 \mathrm{~B}$ & $8,9 \mathrm{~B}$ & $9,1 \mathrm{~B}$ & $9,1 \mathrm{~B}$ & $8,9 \mathrm{~B}$ \\
\hline 2/3 LL & $8,1 \mathrm{C}$ & $8,7 \mathrm{~B}$ & $8,7 \mathrm{~B}$ & $8,3 \mathrm{C}$ & $8,4 \mathrm{C}$ \\
\hline $\mathrm{CN}$ & $7,3 \mathrm{C}$ & $8,3 \mathrm{~B}$ & $8,5 B$ & $8,1 \mathrm{C}$ & $8,0 \mathrm{C}$ \\
\hline Média & 8,9 & 9,2 & 9,3 & 8,9 & 9,1 \\
\hline
\end{tabular}

Médias seguidas da mesma letra minúscula na linha e maiúscula na coluna não diferem $(P<0,05)$ entre si pelo teste Scott-Knott. $\mathrm{SLL}=$ sem linha de leite, $\mathrm{LL}=$ linha de leite, $\mathrm{CN}=$ camada negra . 
bons (a maioria manteve-se abaixo de 30\%). O maior valor de FDA na silagem do cultivar P30S40 no estádio SLL pode ser atribuído às maiores porcentagens de lignina nas silagens desse cultivar, enquanto a menor porcentagem de FDA para este cultivar no estádio 1/2 LL pode ter sido ocasionada pelo menor valor de lignina neste estádio.

Lavezzo et al. (1997b), avaliando cultivares de milho ensilados com os grãos nos estádios leitoso, farináceo, ponto pamonha e semiduro, observaram redução nos teores de FDA nas silagens (de 37,7 para 30,0\%) conforme avançou o estádio de maturação, provavelmente em virtude da maior participação de grãos no material ensilado. Avaliando silagens com diferentes proporções de grãos, Cabral et al. (2002) observaram redução nos teores de FDA de 42,5\%, nas silagens sem grãos, para $17,0 \%$ nas silagens com $60,0 \%$ de grãos. Essa redução nos teores de FDA não foi observada nesta pesquisa, possivelmente em virtude da tendência de lignificação com o avançar do estádio de maturação. Os valores foram semelhantes aos relatados por Melo et al. (1999) e Resende et al. (2003), que registraram valores de FDA de 22,6 a 31,0\% em silagens de milho. No entanto, para os cultivares GNZ 2004 (25,9\%), AG1051 (25,8\%) e P30F90 $(28,7 \%)$ ensilados no estádio de corte $1 / 2 \mathrm{LL}$, os valores obtidos neste estudo foram superiores aos reportados por Mendes (2006), de 23,8; 20,9; e 21,6\%, respectivamente.

A porcentagem de lignina (Tabela 5) variou de 3,6 a 5,6\%, como resultado da tendência de lignificação com o avanço do estádio de maturação. A maior porcentagem de lignina no cultivar P30S40 provavelmente está relacionada à menor participação - embora não significativa - de grãos no material ensilado (31,8\%), ou seja, à maior proporção de material fibroso (colmos e folhas), que contribui para aumento na porcentagem dessa fração. Cabral et al. (2002) também observaram aumento da fração lignina nas silagens com menor proporção de grãos, em decorrência das maiores porcentagens de FDN e FDA e da maior altura de plantas deste cultivar, isto é, à maior participação de material fibroso.

Os valores observados neste estudo foram superiores aos descritos por Filya (2004), de 2,1 a 4,0\% de FDA, no entanto, a média geral foi inferior à observada por Cesarino (2006), de 5,7\%. Essa variação indica diferença entre os cultivares ou efeito de adubação e das condições climáticas

Tabela 5 - Porcentagens de fibra em detergente neutro (FDN), fibra em detergente ácido (FDA) e lignina e digestibilidade in vitro da matéria seca (DIVMS) de silagens de milho colhido em diversos estádios de maturação

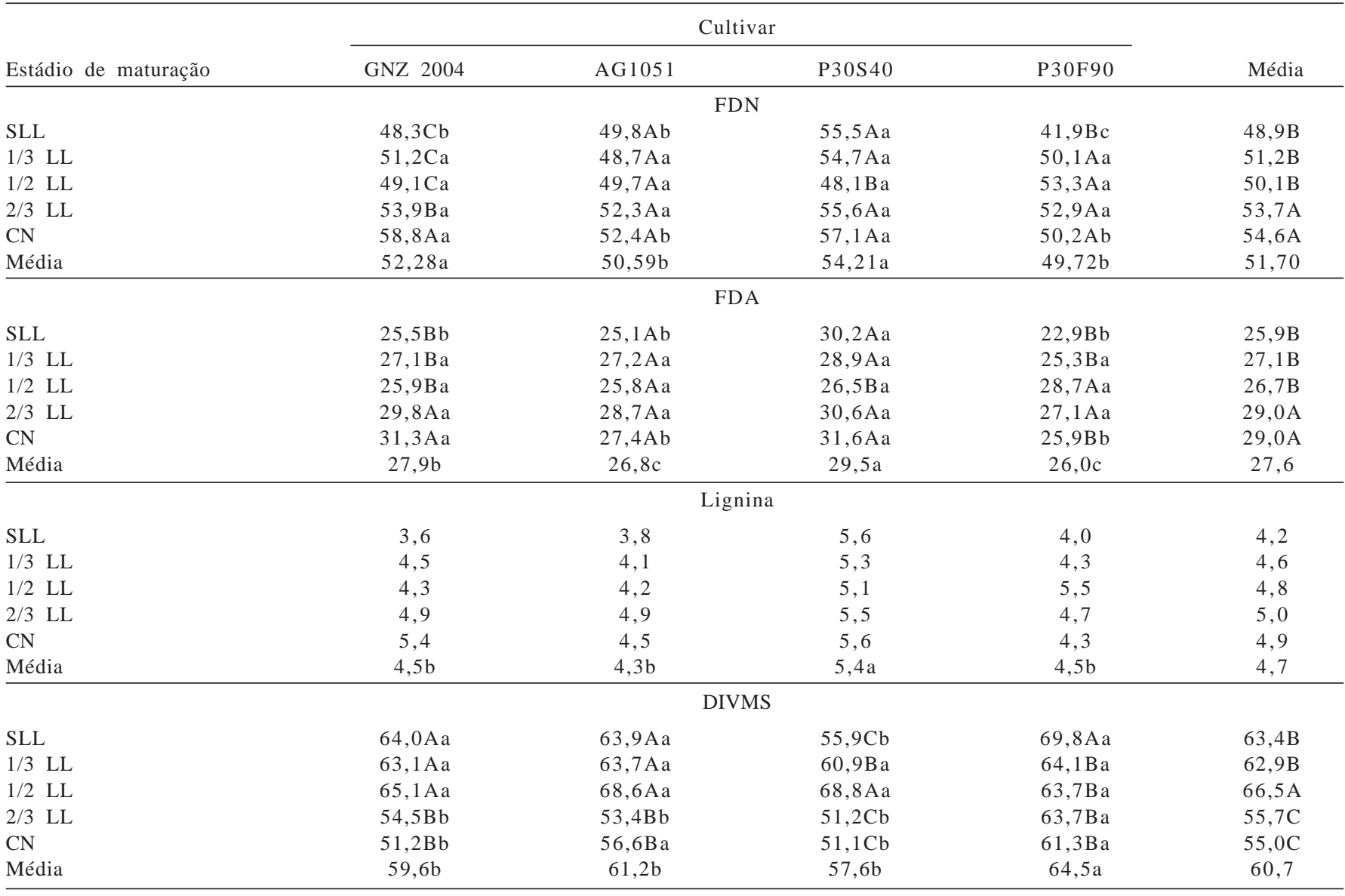

Médias seguidas da mesma letra minúscula na linha e maiúscula na coluna não diferem $(P<0,05)$ entre si pelo teste Scott-Knott. $\mathrm{SLL}=$ sem linha de leite, $\mathrm{LL}=$ linha de leite, $\mathrm{CN}=$ camada negra. 
do local, pois, segundo Ferraz (1996), a elevação da temperatura contribui para o aumento dos constituintes da parede celular.

A digestibilidade in vitro da MS variou de $51,1 \%$, nas silagens do cultivar P30S40 no estádio de corte CN, a 69,8\%, nas silagens do cultivar P30F90 no estádio SLL (Tabela 5). Nas silagens do cultivar GNZ 2004, a DIVMS reduziu nos estádios 2/3 LL e CN, o que está relacionado à elevação nos teores de FDA e à menor digestibilidade do amido nos grãos com o aumento na vitreosidade. O cultivar P30S40 apresentou maior DIVMS quando ensilado no estádio 1/2 LL, o que pode ser explicado pela menor porcentagem de FDA na silagem produzida com esse cultivar neste estádio de maturação, enquanto, para o cultivar P30F90, a maior DIVMS foi observada no estádio SLL, em razão das menores porcentagens de FDN e FDA da forragem ensilada. No estádio de corte SLL, o cultivar P30S40 apresentou menor DIVMS, como resultado da menor porcentagem de MS da forragem ensilada (24,2\%), que causa grande perda de efluente com a perda de nutrientes digestíveis, aumentando a porcentagem de FDA das silagens e reduzindo a DIVMS.

Segundo Nussio (1991), a porcentagem ideal de MS em silagens de milho é de 30 a 37\%. Assim, a maior DIVMS (63,7\%) observada nas silagens do cultivar P30F90 ensilado no estádio 2/3 LL possivelmente foi ocasionada pela menor porcentagem de MS nas silagens deste cultivar (36,4\%) neste estádio de corte, o que reduziu as perdas de nutrientes e provavelmente ocasionou a maior DIVMS. Os cultivares AG1051 e P30F90 no estádio CN apresentaram maior DIVMS, o que pode ser atribuído à menor porcentagem de FDA da forragem neste estádio de corte. De maneira geral, os cultivares ensilados com grãos no estádio 1/2 LL apresentaram maior DIVMS (66,5\%), enquanto, nos estádios de corte 2/3 LL e CN, a DIVMS foi bem menor.

Com a maturação do milho, ocorrem aumento na vitreosidade dos grãos e redução da degradação ruminal (Corrêa et al., 2002). Assim, com o avançar da maturação dos grãos dentados, a vitreosidade aumentou e a degradação ruminal diminuiu, logo, a degradabilidade do híbrido de maior vitreosidade foi mais afetada pelo avanço da maturação. Os resultados de DIVMS observados nesta pesquisa para os cultivares de grãos dentados (AG1051) e semidentados (GNZ 2004 e P30S40) corroboram a afirmativa desses autores, visto que, após o estádio de corte 1/2 LL, houve queda acentuada na DIVMS, o que também pode ser atribuído à maior vitreosidade dos grãos nestes estádios de corte. Os resultados de DIVMS observados para o cultivar P30F90, que possui textura de grão dura e certamente com maior vitreosidade, contrariam os relatos de Corrêa et al. (2002), pois, para esse cultivar, a redução na DIVMS foi menos acentuada, provavelmente em razão da melhor qualidade da fibra deste cultivar em comparação às porcentagens de FDN e FDA no estádio de corte CN.

Cabral et al. (2002), avaliando silagens de milho no estádio farináceo-duro com diferentes proporções de grãos no material ensilado, observaram aumento na DIVMS, de $62,2 \%$, nas silagens sem grãos, para $83,2 \%$, nas silagens com $60,0 \%$ de grãos. De modo geral, a DIVMS neste estudo aumentou até o estádio de corte $1 / 2 \mathrm{LL}$, como resultado do aumento de grãos no material ensilado e dos menores teores de FDN e FDA até este estádio. Após este estádio de maturação, a DIVMS reduziu significativamente, sugerindo que o aumento de grãos no material ensilado não foi suficiente para reduzir as porcentagens de FDN e FDA e diminuiu, portanto, a DIVMS. Esses resultados foram semelhantes aos observados por Lavezzo et al. (1997b), que, avaliando cultivares de milho ensilados com os grãos nos estádios leitoso, farináceo, ponto pamonha e semiduro, observaram coeficientes de digestibilidade aparente da MS que variaram de 57,6 a $65,8 \%$. A média observada $(60,7 \%)$ foi superior à registrada por Cesarino (2006), de $51,6 \%$, em silagens produzidas com milho no estádio de grãos na 1/2 LL.

\section{Conclusões}

Os cultivares GNZ 2004, AG1051 e P30F90 são os mais indicadas para ensilagem. O melhor estádio de maturação para ensilagem desses cultivares é quando os grãos apresentam redução da linha de leite na metade do grão (1/2 LL).

\section{Literatura Citada}

ALLEN, M. All corn silage is not created equal. Fort Atkinson: Hord's Dairyman, 1990. 766p.

AMERICAN ASSOCIATION OF CEREAL CHEMISTS - AACC. Approved methods of the American Association of Cereal Chemists. 7.ed. St. Paul: 1976. 256p.

ASSOCIATION OF OFFICINAL ANALYTICAL CHEMSTS AOAC. Officinal methods of analyses of the Association of Officinal Analytical Chemists. 11.ed. Washington, D.C: 1970. v.1, $1015 p$.

ANDRIEU, J.; DEMARQUILLY, C.; DARDENNE, P. et al. Composition and nutritive value of whole maize plants fed fresh to sheep. 1. Factors of variation. Animal Zootech, v.42, p.221-249, 1993.

BAL, M.A.; SHAVER, R.D.; SHINNERS, K.J. et al. Stage of maturity, processing, and hybrid effects on ruminal in situ disappearance of whole-plant corn silage. Animal Feed Science and Technology, v.86, p.83-94, 2000.

BORREANI, G.; TABACCO, E.; COLOMBARI, G. Influenza del deterioração aeróbico degli insilati sulla qualità dei prodotti caseari. L’informatore Agrário. v.11, p.57-62, 2002. 
CABRAL, L.S.; VALADARES FILHO, S.C.; DETMANN, E. et al. Cinética ruminal das frações de carboidratos, produção de gás, digestibilidade in vitro da matéria seca e ndt estimado da silagem de milho com diferentes proporções de grãos. Revista Brasileira de Zootecnia, v.31, n.6, p.2332-2339, 2002.

CESARINO, R.O. Milho fertirrigado com dejetos líquidos de suínos para ensilagem. Alfenas: Universidade José do Rosário Vellano/UNIFENAS, 2006. 51p. Dissertação (Mestrado em Ciência Animal) - Universidade José do Rosário Vellano/ UNIFENAS, 2006.

COMISSÃO DE FERTILIDADE DO SOLO DO ESTADO DE MINAS GERAIS - CFSEMG. Recomendações para uso de corretivos e fertilizantes em Minas Gerais - $5^{\text {a }}$ aproximação. Viçosa, MG: 1999. 359p.

CÔRREA, C.E.S.; SHAVER, R.D.; PEREIRA, M.N. et al. Relationship between corn vitreousness and ruminal in situ starch degradability. Journal of Dairy Science, v.85, n.11, p.30083012, 2002.

COORS, J.G.; ALBRECHT, K.A.; BURES, E.J. Ear-fill effects on yield and quality of silage corn. Crop Science, v.37, p.243247, 1997.

DEMARQUILLY, C. Facteurs de variation de la valeur nutritive dumais ensilage. Production Animal, v.7, n.3, p.177-189, 1994.

FAnCELli, A.L.; DOURADO Neto, D. Produção de milho. Guaíba: Agropecuária, 2000. 360p.

FERRAZ, E.C. Fisiologia do milho. In: Instituto Brasileiro da Potassa (Ed.) Cultura e adubação do milho. São Paulo: Instituto Brasileiro da Potassa, 1966. p.369-379.

FERREIRA, D.F. SISVAR: Sistema de Análise de Variância. Lavras: UFLA - DEX. 2000. (CD-ROM).

FILYA, L. Nutritive value and aerobic stability of whole crop maize silage harvested at four stages of maturity. Animal Feed Science and Technology, v.116, p.141-150, 2004.

HAIGH, P.M. Effluent production from grass treated with additives and maide in large scale bunker silos. Grass and Forage Science, v.54, p.208-218, 1999.

LAVEZZO, W.; LAVEZZO, O.E.N.M.; CAMPOS NETO, O. Estádio de desenvolvimento do milho. 1. Efeito sobre a produção, composição da planta e qualidade da silagem. Revista Brasileira de Zootecnia, v.26, n.4, p.675-682, 1997a.

LAVEZZO, O.E.N.M.; LAVEZZO, W.; SIQUEIRA, E.R. Estádio de desenvolvimento do milho. 2. Efeito sobre o consumo e a digestibilidade da silagem em ovinos. Revista Brasileira de Zootecnia, v.26, n.4, p.675-682, 1997b.

MAYOMBO, A.P.; DUFRASNE, I.; HORNICK, J.L. et al. Influencie du stade de maturité de la plante de may recolteé pour ensilage sur la composition, la digestibilité aparente, lês caractéristiques de fermentation dans le rume et les performances zootechniques chez le taurillon à I'engraissement. Animal Zootech, v.46, p.43-55, 1997.

MELO, W.M.C.; von PINHO, R.G.; CARVALHO, M.L.M. et al. Avaliação de cultivares de milho para produção de silagem na região de Lavras - MG. Ciência e Agrotecnologia, v.23, n.1, p.31-39, 1999.

MENDES, M.C. Desempenho de híbridos comerciais e experimentais de milho obtidos a partir de linhagens de alta e baixa degradabilidade ruminal da matéria seca.
Lavras: Universidade Federal de Lavras, 2006. 57p. Dissertação (Mestrado em Fitotecnia) - Universidade Federal de Lavras, 2006.

NUSSIO, L.G. Cultura do milho para produção de silagem de alto valor alimentício. In: SIMPÓSIO SOBRE NUTRIÇÃO DE BOVINOS, 4. 1991, Piracicaba. Anais...Piracicaba: Fundação de Estudos Agrários Luiz de Queiroz, 1991. p.58-168.

NUSSIO, L.C. Avaliação de cultivares de milho (Zea mays L.) para ensilagem através da composição química e digestibilidade in situ. Piracicaba: Escola Superior de Agricultura Luiz de Queiroz, 1997. 58p. Dissertação (Mestrado em Ciência Animal e Pastagens) - Escola Superior de Agricultura Luiz de Queiroz, 1997.

O’DONNELL, C.O.; WILLIANS, A.G.; BIDDLESTONE, A.J. The effect of pressure and stage of ensilage on the mechanical properties and effluents production potential of grass silage. Grass and Forage Science, v.52, n.1, p.12-56, 1997.

REIS, R.A.; ROSA, B. Suplementação volumosa: conservação do excedente das pastagens. In: SIMPÓSIO SOBRE MANEJO DA PASTAGEM, 18., 2001, Piracicaba. Anais... Piracicaba: Escola Superior de Agricultura Luiz de Queiroz, 2001. p.193-232.

RESENDE, J.A.; PEREIRA, M.N.; von PINHO, R.G. et al. Ruminal silage degradability and productivity of forage and grain-type sorghum cultivars. Scientia Agricola, v.60, n.3, p.457463, 2003

RODRIGUES, J.A.S.; SILVA, F.E.; GONÇALVES, L.C. Silagem de diferentes cultivares de sorgo forrageiro colhidos em diversos estádios de desenvolvimento. In: CONGRESSO NACIONAL DE MILHO E SORGO, 21., 1996, Londrina. Anais... Londrina: Instituto Agronômico do Paraná, 1996. p.269.

SCHWARS, F.J.; PEX, E.J.; KIRCHGESSNER, M. Influence of different maize varieties on digestibility and energy content of maize silage by cattle and sheep. Wirtschaftseigene - Futter, v.42, n.2, p.161-172, 1996.

SILVA, A.C. Dinâmica da cobertura pedológica de uma área cratônica do sul de Minas Gerais. Piracicaba: Escola Superior de Agricultura Luiz de Queiroz, 1997. 191p. Tese (Doutorado em Solos e Nutrição de Plantas) - Escola Superior de Agricultura Luiz de Queiroz, 1997.

SILVA, D.J.; QUEIROZ, A.C. Análise de alimentos: métodos químicos e biológicos. 3.ed. Viçosa, MG: Editora UFV, 2002. 235p.

SILVA, A.V.; PEREIRA, O.G.; GARCIA, R. et al. Composição bromatológica e digestibilidade in vitro da matéria seca de silagens de milho e sorgo tratadas com inoculantes microbianos. Revista Brasileira de Zootecnia, v.34, n.6, p.1881-1890, 2005.

Van SOEST, P.J. Nutritional ecology of the ruminant. New York: Cornell University Press, 476p. 1994.

Van SOEST, P.J.; ROBERTSON, J.B.; LEWIS, B.A. Methods for dietary fiber, neutral detergent fiber, and nonstarch polysaccharides in relation to animal nutrition. Journal of Dairy Science, v.74, n.10, p.3583-3597, 1991.

Villela, T.E.A. Época de semeadura e de corte de plantas de milho para ensilar. Lavras: Universidade Federal de Lavras, 2001. 86p. Dissertação (Mestrado em Fitotecnia) - Universidade Federal de Lavras, 2001.

WOOLFORD, M.K. The silage fermentation. New York: Marcel Dekker, 1984. 350p. 